\title{
$\begin{array}{ll}\text { Research Square } & \text { Preprints are preliminary reports that have not undergone peer review. } \\ \text { They should not be considered conclusive, used to inform clinical practice, }\end{array}$
}

\section{CTCs Detection from Intraoperative Salvaged Blood in RCC-IVC Thrombus Patients by Negative Enrichment and iFISH Identification - A Preliminary Study}

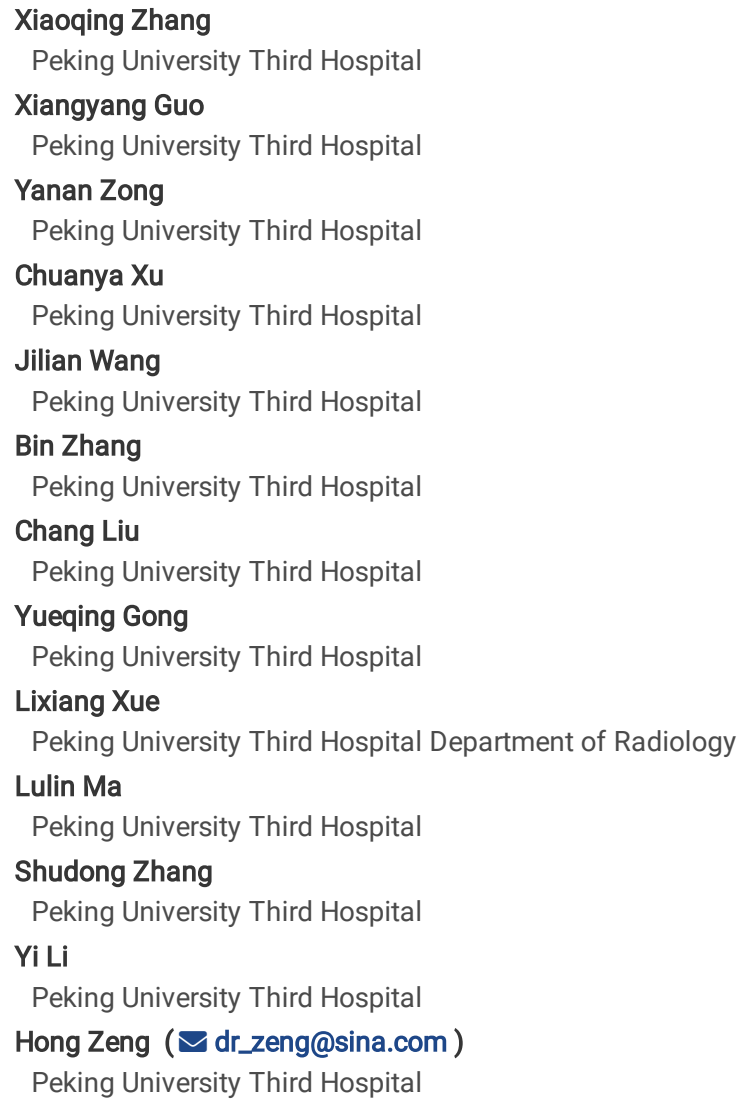

Research article

Keywords: renal cell carcinoma, inferior vena cava thrombus, intra-operative cell salvage, leukocyte depletion filter, aneuploidy.

Posted Date: October 14th, 2020

DOI: https://doi.org/10.21203/rs.3.rs-71616/v1

License: (9) (7) This work is licensed under a Creative Commons Attribution 4.0 International License. Read Full License

Version of Record: A version of this preprint was published at BMC Urology on June 10th, 2021. See the published version at https://doi.org/10.1186/s12894021-00803-w. 


\section{Abstract}

Background: Intra-operative cell salvage (IOCS) and leukocyte-depleted filter (LDF) are widely used and effective in saving blood. However, the safety issue concerning reinfusion of IOCS-LDF processed blood to renal cell carcinoma (RCC) patients with inferior vena cava (IVC) thrombus were inconclusive for fear of increased risk of cancer metastases. This study intends to analyze the circulating tumor cell (CTC) eliminating effect of IOCS-LDF in 5 RCC-IVC thrombus patients.

Methods: A novel strategy integrating negative enrichment by immunomagnetic beads and immunostaining-fluorescence in situ hybridization with probes identifying aneuploid of 8 and/or 7 were used to detect CTCs from salvages blood. Blood samples were collected from 4 stages in each patient.

Results: The CTCs number decreased (from 3, 4, 10, 7, 3, respectively, to all zero) after IOCS-LDF treatment. And the triploidy of chrmosome 7 and/or chromosome 8 were most common karyotype for RCC patients with IVC thrombus. Tetraploid of chromosome 8 concurred in only one sample and no polypoid (number of chromosome $₫ 4$ ) were found.

Conclusion: IOCS-LDF might be a viable option for reduction of allogeneic product transfusion based on current preliminary outcome. More convincing conclusions are to be drawn with enlarged sample size and long-term follow-up of patients prognosis.

\section{Background}

Renal cell carcinoma (RCC) ranks the sixth most frequently diagnosed cancer in men and the 10th in women worldwide. It is the 13th most common cause of cancer death worldwide according to data provided by the World Health Organization, as more than 140,000 RCC-related deaths yearly. The incidence rates of RCC is still rising, and this is partially because the increase in the imaging examination. Although most detected lesions are small tumors, locally advanced disease continues to be diagnosed in a notable proportion of patients, with up to $17 \%$ of patients harboring distant metastases at the time of diagnosis [1].

It is observed in $4-10 \%$ RCC patients who have a unique propensity for vascular invasion (into the renal vein and inferior vena cava) in the advanced stage [2]. Current guidelines recommend surgical excision of non-metastatic RCC with inferior vena cava (IVC) thrombosis in patients with acceptable performance status [3]. Patients with RCC - IVC tumor thrombus had a significant blood loss during operation despite improvements in surgical technique. The median estimated blood loss was 1900 (IQR 800-3300) ml. For patients with thrombus level $\leq 2$ and $\geq 3$ (Mayo-level), the blood loss were 1500 (IQR 600-2875) ml and 3000 (IQR 1400-5350) ml, respectively [4]. Massive transfusion of allogeneic blood may cause bacterial infection, allergic reactions, hemolytic reactions, transfusion-related risks of acute lung injury and viral infections. In addition, the banked blood has low oxygen carrying capacity and impaired red blood cell viability [5]. Immune reactions may occur during allogeneic blood transfusion, leading to acute cell rejection. Allogeneic transfusion is an independent risk factor for cancer-specific mortality and overall mortality in patients with malignancies [6]. It is concerned that allogeneic transfusion may result in immunosuppression and possible adverse effects on urological cancer recurrence $[7,8]$.

Intra-operative cell salvage (IOCS) is of great significance in saving blood and offers an efficacious, alternative technique for blood replacement. Leukocytedepleted filter (LDF) is normally used after IOCS washing and before infusion to remove nucleated cells such as bacteria and tumor cells. At present, IOCS is widely used in many surgeries like cardiac surgery and spinal orthopedic surgery [9]. Guidance from the UK National Institute for Health and Clinical Excellence (NICE) recommends the routine use of IOCS in all patients undergoing radical pelvic urological surgery in 2008 [10]. Though several meta-analysis of longterm follow up of cancerous patients after IOCS-LDF use were reported with no apparent risk of decreased long-term survival from oncological perspective [5,11], concerns regarding the increased risk of cancer recurrence or development of metastases resulting from re-infusion of malignant cells renders the reluctance of adopting IOCS-LDF. At present, there were few studies on the safety assessment of recovered blood in patients with RCC-IVC thrombus. This study intends to analyze the tumor cell eliminating effect of IOCS-LDF in patients with RCC-IVC thrombus with a novel strategy integrating negative enrichment by immunomagnetic beads and immunostaining fluorescence in situ hybridization (NE-iFISH) with probes identifying aneuploidy.

\section{Method}

\subsection{Patients selection}

We recruited patients with RCC-IVC thrombus underwent open/laparoscopy radical nephrectomy and IVC tumor thrombectomy from January to December, 2018 in Peking University Third Hospital. Thrombus level was defined according to Mayo classification [12]. Only RCC - IVC thrombus (Mayo-levels II-IV) were included in the study. Excluding criteria: patients with blood diseases, infectious diseases, and those who refused to participate in the study. The study was approved by the hospital ethics committee (No. M2017296), and patients and their families all signed informed consent. Patients' demographic information were recorded (Table 1).

\subsection{Anesthesia and surgical methods:}

General anesthesia was performed. Patients' vital signs were closely monitored and the depth of anesthesia was adjusted according to surgical stimulus, BIS and dynamic circulation variation. Allogeneic blood transfusion was used according to transfusion guidelines and therapies. The surgery of open/laparoscopy radical nephrectomy and IVC tumor thrombectomy were dictated by the extent and level of the tumor thrombus, and the surgical technique has been described in detail by Berczi [13]. Surgical time, intraoperative blood loss, the amount of autologous blood recovery, and the amount of allogeneic blood transfusion were recorded. Recovered blood was not re-infused as this was not allowed by the ethical committee for fear of tumor dissemination and subsequent risk of metastatic disease. Tumor recurrence rate was investigated at 20 months follow up. 
The suction tube and blood reservoir of the IOCS machine (Cell Saver Elite, Haemonetics Corporation, MA, U.S. ) was rinsed and pre-filled with 50-100ml anticoagulant saline (heparin saline, $500 \mathrm{lU} / \mathrm{ml}$ ). The negative pressure of the suction device is set at $120-150 \mathrm{mmHg}$. The anticoagulant drip rate was adjusted to about $1 \mathrm{drop} /$ second, and the flow rate was adjusted according to the amount and speed of the bleeding. All intraoperative shed blood was recovered from the skin incision to tumor removal. Recovered blood was anti-coagulated and washed with sterilized saline (1500-2000 $\mathrm{ml}$ for $250 \mathrm{ml}$ RBC). After washing, the recruited blood was filtered through PALL ${ }^{\circledR}$ leukocyte reduction filter (SB, Haemonetics Corporation, MA, U.S.). Blood products treated with IOCS - LDF are for research use only and are not returned to patients.

\subsection{Sample preparation}

Blood samples were collected intraoperatively at 4 different stages and sites (S1, peripheral venous blood from internal jugular vein before skin incision; S2, blood sampled in the vena cava around the tumor thrombus during surgery; S3, IOCS blood after washing and before LDF filtering; S4, blood sampled from post-LDF filtration). Each sample contains $4.0 \mathrm{ml}$ blood (figure 1).

\subsection{Negative Enrichment of CTC}

The strategy of enrichment for circulating tumor cell (CTCs) is performed according to manufacture's instructions. Briefly, 4.0 ml blood samples were lysed by RBC hypotonic hemolysis. Solution was centrifuged at $300 \times \mathrm{g}$ for $5 \mathrm{~min}$. Then, the residue cell pellet was resuspended in PBS and subsequently incubated with anti-CD45 monoclonal antibody-coated magnetic beads for 30 min, followed by the separation of magnetic beads using a magnetic stand (Promega, Madison, WI, USA). Supernatants were subsequently subjected to identification.

\subsection{Immunocytochemistry staining of CTCs}

The identification of enriched CTCs was performed by combing the chromosome enumeration using fluorescence in situ hybridization (FISH) with chromosome 7 (green) and 8 (orange) centromere probes (Abbott Molecular Diagnostics, Des Plaines, IL, USA) and anti-CD45 monoclonal antibody (red) (CD45-FISH). Probe chromosome 7 (CEP7, green), chromosome 8 (CEP8, orange) and specimen were hybridized at $37^{\circ} \mathrm{Cfor} 20$ min in hybridizer (DAKO). Then they were washed in $50 \%$ formamide at $43^{\circ} \mathrm{C}$ for $15 \mathrm{~min}$, and subsequently immersed into $2 * \mathrm{SSC}$ and gradient alcohol again. Specimens were washed twice with $0.2 \%$ BSA and incubated with the CD 45 mixture/2 \%BSA conjugated to Alexa Fluor 594 (Invitrogen) for 1 h. Afterward, samples were washed again with $0.2 \%$ BSA, and covered with DAPI which contained Vectashield mounting medium [14]. CTCs were examined and identified as hyperdiploid CEP8+/DAPI+/CD45-, hyperdiploid CEP7+/DAPI+/CD45- and hyperdiploid CEP7+, 8+/DAPI+/CD45- by two independent pathologists, while cells with CD45+ were differentiated as WBC.

\subsection{Statistical Analysis}

All data were recorded and compared among 5 RCC-IVC thrombus patients. Medians and quartiles were used to describe the amount of intraoperative blood loss, transfusion and recovered blood.

\section{Results}

\subsection{Demographic Information}

In the current study, a total of 5 patients with RCC - IVC thrombus were included for surgical treatment. Of all these 5 patients, one (case No. 2) underwent radical nephrectomy of the right kidney due to renal cancer in local hospital 3 years ago. The patient complaint shortness of breath recently and was admitted to our hospital. His lung CT revealed multiple nodules in both lungs, indicative of metastasis $(4.1 \mathrm{~cm} * 3.8 \mathrm{~cm})$. Abdominal CT revealed IVC thrombosis which was operated later and diagnosed from clear cell renal cell carcinoma origin by pathological examination. The size of the renal tumors of the other four patients were $7.1 \mathrm{~cm} * 5.2 \mathrm{~cm} * 4.6 \mathrm{~cm}, 12 \mathrm{~cm} * 10 \mathrm{~cm} * 6 \mathrm{~cm}, 5 \mathrm{~cm} * 3 \mathrm{~cm} * 2.5 \mathrm{~cm}, 9 \mathrm{~cm} * 5 \mathrm{~cm} * 4 \mathrm{~cm}$, respectively, and the WHO/ISUP grading system of the tumors were G2, G3, G2, G3, respectively [15] (Table 2). The pathological diagnosis of all 5 patients were clear cell renal cell carcinoma (ccRCC) (Figure 2). Post-operative follow-up showed the patient (case No. 2) with radical nephrectomy history died of emphysema 16 months after thrombectomy. Other 4 patients were closely followed up for at least 20 months and no cancer recurrence or metastasis were found till now.

\subsection{Intraoperative blood loss and recovery}

A total of 5 patients (ASA II - III) were enrolled, including 1 female and 4 male patients, with an averaged age of 58.6 years. 3 patients (2 with Mayo-levels II, and 1 with Mayo-level IV) underwent open radical nephrectomy and IVC tumor thrombectomy, 1 (Mayo-level III) with open thrombectomy, and 1 patient (Mayo-level II) received laparoscopic radical nephrectomy and IVC tumor thrombectomy. Surgical duration was 335 (IQR, 320 - 540) min. The total intraoperative blood loss was 10,500 ml, 2100 (IQR, 1500 - 2700) ml, with one patient (Mayo-level IV) lost $4000 \mathrm{ml}$. The amount of transfused allogeneic red blood cells was 8800 $\mathrm{ml}, 2000$ (IQR, 1200 - 2000) $\mathrm{ml}$; and the amount of transfused plasma was $2800 \mathrm{ml}$. One patient (Mayo-level II) who underwent laparoscopic radical nephrectomy and IVC tumor thrombectomy did not receive allogeneic blood transfusion due to small amount of blood loss. A total amount of $5150 \mathrm{ml}$ of autologous blood, $1000 \mathrm{ml}(750,1300)$ was recovered during surgery (Table 2). One patient (Mayo-level IV) experienced major bleeding and was managed with vasoactive drugs and massive blood product transfusion and fluid resuscitation. All patients' vital signs were stable during hospitalization.

\subsection{Detection of tumor cells}

20 blood samples from 5 RCC-IVC thrombus patients were studied. After excluding CD45+ leukocytes by immunomagnetic beads, the aneuploidy (abnormal chromosome numbers) of chromosome 8 and/or 7 were detected with iFISH examination. The aneuploidy of chromosome 8 or 7 include: trisomy 8 , 
tetraploidy 8 , polyploidy $8(\varangle 4)$, trisomy 7 , tetraploidy 7 , polyploidy $7(\varangle 4)$, aberrant number of both chromosome 8 and 7 , and circulating tumor microemboli (CTM). The negative expression of CD45 and the aneuploidy of chromosomes 8 and/or 7 (chromosome number冈2) were discriminated as CTCs (Table 3).

In all S1 samples, the number of tumor cells in the peripheral blood were 3, 4, 10, 7 and 3, respectively; and the number of tumor cells in the S2 sample were 0 , $0,2,5$ and 1, respectively; in S3 samples, the number of tumor cells decreased to 1, 0, 0, 0 and 0; and no tumor cell was found in any sample in S4 group ( 0,0 , $0,0,0)$.

In this preliminary study, most CTCs were of triploidy of chromosome 8 (5/5 cases in S1, 2/5 cases in S2 and 1/5 cases in S3) or chromosome 7 (4/5 cases in S1, $3 / 5$ cases in S2, and 1/5cases in S3), while only 1 case with tetraploidy of chromosome 8 . The hyperdiploidy of both chormosome 7 and 8 were detected in 3 cases ( 2 cases of $\mathrm{S} 1$ and 1 case of S2). No tetraploidy of chromosome 7, or other aberrant chromosome number $\geq 4$ were detected. (Table 4 ).

\section{Discussion}

\subsection{Aneuploidy of detected viable tumor cells}

Intraoperative tumor metastasis occurred when large amounts of cancer cells were shed from primary tumor focus during surgical manipulation into the blood stream, becoming circulating tumor cells (CTC) and may target distant organs and develop metastatic tumors [16]. Reinfusion of viable tumor cells from intraoperative recovered blood poses potential risks of tumor dissemination and metastasis. However, due to scarce number of residual tumor cells from vast majority of leukocytes, capturing viable tumor cells from shed blood after IOCS-LDF treatment is difficult. Mi Sook Gwak reported using LDF to reduce the risk of reintroduction of hepatocellular carcinoma cells with PCR found that at high HCC cell load the filter cannot completely remove all the tumor cells[17]. Though PCR can detect CTCs gene copy numbers, accurate enumeration of CTCs by this strategy is not feasible [18]. Moreover, this method could not completely eliminate the interference from fragmented DNA in sampled blood. Other studies analyzed the remaining tumor cells using flow cytometry or immunohistopathologcial study in cell blocks or cultured cells found that no viable tumor cells could be detected or if there were any tumor cells found, the load was far less than the CTC numbers in the patients' circulation $[19,20]$. However, restricted to the sensitivity and specificity of the above mentioned technologies, the isolation and capturing of viable tumor cells which were only several to several tens of number present in $1 \mathrm{ml}$ of blood that contains billions of other cells were extremely difficult.

Currently, the majority of the methodology of detecting CTCs are restricted to the tumor cell density, size, and charge as well as biomarkers using antigen expression profiles and specific tumor antigen-antibody interactions to distinguish and isolate CTCs from other cells. However, a large quantity of primary CTCs are of smaller cell size ( $\leq$ WBCs) which makes it difficult to separate from WBC, and the rare CTCs are inevitability lost during filtration based cell size selection strategy [21]. Moreover, it is reported that positive EpCAM experssion rate ranges $37 \%-42.3 \%$ of the various cancers with FDA-approved CellSearch system. The invasive tumor cells tend to loose their epithelial antigens by the epithelial to mesenchymal transition process, which results in loss of EpCAM on CTCs and made the capturing of CTCs more difficult [22]. On the other hand, capturing non-tumor derived epithelial cells originated from inflammation, trauma, surgery and benign epithelial hyperplasia may cause false positive results [23]. For renal cell carcinoma, the expression of EpCAM was absent and there is no widely acknowledged specific cell surface marker for RCC detection[24,25]. Therefore, a promising alternative approach of EpCAM-independent enrichment strategy has been introduced [26].

In this preliminary study, detecting aberrant chromosome is attempted as a way of capturing tumor cells in RCC patients. Aneuploidy is the abnormal alternation (either gain or loss) of chromosomes in a cell. It is estimated that $90 \%$ of solid tumors exhibit aneuploidy [21]. By integrating cellular and molecular approach of negative enrichment and immunostaining-fluorescence in situ hybridization (NE-iFISH), which is independent of cell size variation and free of anti-EpCAM perturbing, iFISH could simultaneously co-detecting biomarker expression qualitatively and quantitatively, as well as discovering chromosome aneuploidy $[14,27]$.

It is reported that unique molecular alterations such as loss of 3p and trisomy of chromosomes 7 is well characterized for clear cell and papillary RCC [28-31]. After negative enrichment, tumor cells are identified by iFISH. Aneuploidy of chromosome 8 and/or 7 were analyzed and tumor cells were differentiated (figure 3). In this way, we could separate CTCs from recovered blood in RCC with IVC thrombus patients. To our knowledge, this is the first time that aneuploidy of aberrent chormosome detection method was adopted with NE-iFISH to capture CTCs in the recovered blood of ccRCC patients with encouraging result.

It is interesting to note that CTCs recovered from intraoperative blood in CCRCC -IVC thrombus patients have the propensity of developing trisomy of chormosome 7 or 8 . This chormosome karyotype was not reported before and deserve further exploration. It may be useful for future chromosome karyotype analysis and also for further study of the clinical significance in treatment efficacy of tumor recurrence, metastasis detection and prognosis.

\subsection{IOCS-LDF and RCC metastasis}

Radical nephrectomy and IVC tumor thrombectomy is widely acknowledged as the curative method for patients with RCC-IVC thrombus [32]. When the tumor thrombus extends to the right atrium, intraoperative establishment of extracorporeal circulation is required. Patients with Mayo-level III-IV often experienced life-threatening intraoperative major bleeding. As blood resource is limited, scheduled surgeries are always delayed. A recent meta-analysis has shown that the infusion of allogeneic blood during radical prostatectomy, radical nephrectomy and cystectomy lead to worsened prognosis for patients [33], and this may be related to transfusion-related immunomodulation [34]. The application of IOCS-LDF is an effective alternative for massive blood transfusion. A study concerning the IVC tumor thrombus extending to right atrium has shown that the use of cardiopulmonary bypass and cell-saver technique in borderline situations like combined oncologic and cardiovascular surgery without increasing the risk of hematogenous tumor dissemination. Postoperative cytological investigation showed that the tumor cells were only found on the internal surface of the heart-lung machine arterial filters. No distant metastasis was found in all surviving patients [35]. 
There were limited clinical study concerning the safety of returning shed blood to RCC - IVC thrombus patients. Moskowitz reported a Jehovah's Witness patient with RCC-IVC thrombus extending into the right atrium underwent surgery received the return of $3 \mathrm{~L}$ of salvaged erythrocytes during surgery without immediate complication, but the patient's long-term outcome was not reported ${ }^{[16]}$. A study including 10 patients underwent radical nephrectomy with IVC and atrial thrombi surgery was followed-up for 46 months. Unfortunately, the only use of IOCS in conjunction with cardiopulmonary bypass renders the conclusions difficult to ascertain, and comparisons between the usage of IOCS are confounded by disease severity and level of caval thrombus [36] .

Timothy D reported 67 renal cancer patients undergone partial nephrectomy using IOCS-LDF without increasing postoperative complications or tumor recurrence, and 2 years of follow-up showed no metastasis [37]. Another retrospective cohort study was performed to assess the impact of intra-operative cell salvage on outcomes in open nephrectomy with 16 patients using IOCS and 24 without, concluding that IOCS appears to be a safe way with low rates of tumor recurrence and complications [38]. A meta-analysis in 2019 systematically evaluated the safety and effectiveness of IOCS in urological procedures by comparing the rate of allogeneic blood transfusion and tumor recurrence, complications, and medical costs. For the 14 observational studies (4536 patients) that were finally included, compared with other blood protection methods, IOCS was considered to reduce the rate of allogeneic blood transfusions and reduce medical costs, without affecting the incidence of complications. The author concluded from 10 studies that tumor recurrence was found to be significantly less common or similar in IOCS group. Eight of the studies were performed on prostate surgery, and only one was followed up for more than 5 years [39]. For nephrectomy and cystectomy, tumor recurrence after IOCS needs to be further studied.

\subsection{Leukocyte filter and tumor cell filtration}

Leukocyte depletion filter (LDF) is a filtering device based on a membrane-like filter material to remove leukocytes from blood. Its mechanism for removing tumor cells is physical interception and charge adsorption based on cell size. Study from hepatocellular carcinoma cells has shown that once the cell number exceeds $1 \times 10^{5}$, LDF cannot effectively filter tumor cells [40]. Hanse compared 9 different LDF filters and found that the reduction rates of tumor cell lines is within the range of $4-5 \mathrm{log}$, but only 3 log of prepared cells from solid tumor could be filtered. It is estimated that up to $10^{7}$ tumor cells were shed during oncologic surgery, therefore it is unsafe to return autologous blood after LDF filtration [41]. In many types of tumor surgery, the actual number of shed tumor cells ranges approximately $0.2-4000 / \mathrm{ml}$ [42]. Existing evidence suggested that only for malignancies of advanced stage or tumor rupture during surgery can there be possibilities of ineffective clearance of LDF. Kai Mei and colleague reported by applying mannitol-adenine-phosphate (MAP) solution, the tumor cell clearance rate was increased from 2-3 log to 4-5 log with modified-LDF (M-LDF). For blood mixed with HepG2 cell $\left(10^{6}-10^{7}\right), 67 \%$ inoculated nude mice developed tumors with unfiltered blood, while no solid tumor appeared in inoculated nude mice after filtering with M-LDF [43]. Therefore, it is considered that M-LDF with MAP had higher filter efficiency, but further clinical evidence is warranted. In the current study, we demonstrated with aneuploidy method, all the tumor cells in 5 patients were completely removed after LDF treatment, and intraoperative IOCS-LDF usage could clear all tumor cells in RCC - IVC thrombus patients with high efficiency.

\subsection{IOCS-LDF for RCC-IVC thrombus tumor cell removal}

In this study, 5 RCC - IVC thrombus patients were enrolled and 20 blood samples taken at different sites and stages during surgery were studied. Samples of S1 is indicative of the circulating tumor cells; S2 indicated peri-thrombus tumor cells shedding into inferior vena cava during operation; S3 represents the tumor cell cleaning efficacy with IOCS; and S4 is the actual final filtering result after LDF. Tumor cell numbers from all S4 samples were zero after IOCS-LDF treatment. This demonstrated that IOCS-LDF is effective in removing tumor cells. To our surprise, the number of tumor cells in internal jugular vein from $\mathrm{S} 1$ is most abundant $(3,4,10,7$ and 3 , respectively), while the number from $S 2$ decreased dramatically $(0,0,2,5$ and 1$)$. This might be explained by the solid texture of the IVC thrombus and its smooth surface which could extend itself way up to the atrium without being flushed away by blood flow in the inferior vena cava. This also indicate that intraoperative exploration of the tumor thrombus does not necessarily result in significant shedding of tumor cells which might lead to tumor dissemination. Our study also demonstrated that IOCS alone is not enough for tumor cell depletion as CTCs were still detected in $2 / 5$ cases from S3. The IOCS-LDF is efficient in depleting tumor cells from recovered blood as the number of CTCs reduced to 0 in all S4 samples. Due to limited sample size, further research with enlarge sample size is needed to verify the clearance ability of IOCS-LDF on RCC-IVC thrombus cases. Considering cell size differences, the application of IOCS-LDF to other tumor types may not achieve the equivalent effect.

Moreover, we also found that there is no close correlation between the amount of blood loss and the number of CTCs from the current study, which was also stated by Ernil Hansen in their research [42]. The number of CTCs were more prominent in patients with more advanced tumor stage and higher WHO-ISUP grading as well as Mayo-level grading. In case 3 and 4, the Mayo-level grading were II and IV, and the WHO-ISUP grading were G3 and G2, respectively. In case 3 , the number of CTCs were 10 (S1) and 3 (S2), and the size of the dissected tumor is $12 \mathrm{~cm} * 10 \mathrm{~cm} * 6 \mathrm{~cm}$; wile for case 4 , the number of CTCs were 7 (S1) and 5 (S2), with the size of the dissected tumor $5 \mathrm{~cm} \star 3 \mathrm{~cm} \star 2.5 \mathrm{~cm}$. However, it is arbitrary to reach any definitive conclusion based on the limited sample size. Further research is warranted in verifying this finding.

\section{Conclusion}

As there were no definitive guidelines or experts consensus to support the intraoperative use of LOCS-LDF in renal cell carcinoma patients, and the safety of laboratory and clinical evidence of reinfusion of autologous blood is lacking, therefore, our hospital forbid this procedure and only allow the experimental study of tumor cell deleting effect of the IOCS-LDF. In this preliminary study, CTCs of all samples decreased to 0 after IOCS-LDF in all five RCC-IVC thrombus patients detected by NE-iFISH, with encouraging results. More convincing conclusions are to be drawn with enlarged sample size and discovery of more specific and accurate bio-markers for tumor cells originated from RCC-IVC thrombus.

\section{List Of Abbreviations}


IOCS: Intra-operative cell salvage

LDF: leukocyte-depleted filter

RCC: renal cell carcinoma

IVC: inferior vena cava

CTC: circulating tumor cell

NE-iFISH: negative enrichment by immunomagnetic beads and immunostaining fluorescence in situ hybridization

FISH: fluorescence in situ hybridization

M-LDF: modified-LDF

MAP: mannitol-adenine-phosphate

\section{Declarations}

\section{Ethics approval and consent to participate}

The experimental protocol was established, according to the ethical guidelines of the Helsinki Declaration and was approved by the Human Ethics Committee of Peking University Third Hospital. Written informed consent was obtained from individual participants

\section{Availability of data and material}

All data generated or analysed during this study are included in this published article.

\section{Competing interests}

The author(s) declare no competing interests.

\section{Funding}

This work was supported by the Clinical Key Project of Peking University Third Hospital, Grants No. BYSY2017001.

\section{Authors' contributions}

Guarantor of integrity of entire study: $\mathrm{H}$ Zeng, Y Li, XY Guo

Study concepts Study design: H Zeng, XY Guo

Literature research: XQ Zhang, XY Guo, JL Wang

Clinical studies: XQ Zhang, YN Zong, CY Xu, B Zhang, C Liu

experimental studies: XQ Zhang, YQ Gong, LX Xue

Data acquisition: XQ Zhang, LL Ma, SD Zhang

Data analysis/interpretation: XQ Zhang, Y Li, H Zeng

Statistical analysis: XQ Zhang, XY Guo, JL Wang

Manuscript preparation: XQ Zhang, XY Guo, JL Wang, YQ Gong, LX Xue, H Zeng

Manuscript editing and revision: Y Li, H Zeng, XY Guo, JL Wang

Manuscript final version approval: H Zeng, XY Guo

all authors have read and approved the manuscript.

\section{Acknowledgments}

None.

\section{References}

1. Capitanio U, Bensalah K, Bex A, et al. Epidemiology of Renal Cell Carcinoma. Eur Urol. 2019;75:74-84. https://doi.org/10.1016/j.eururo.2018.08.036. 
2. Wein AJ, Kavoussi LR, Partin AW, Peters CA. (2016) Campbell's Urology (ed 11). Malignant Renal Tumors, Elsevier.

3. Campi R, Tellini R, Sessa F, et al. Techniques and outcomes of minimally-invasive surgery for nonmetastatic renal cell carcinoma with inferior vena cava thrombosis: a systematic review of the literature. Minerva Urol Nefrol. 2019;71:339-58. https://doi.org/10.23736/S0393-2249.19.03396-4.

4. Lue K, Russell CM, Fisher J, et al (2015) Predictors of Postoperative Complications in Patients Who Undergo Radical Nephrectomy and IVC Thrombectomy: A Large Contemporary Tertiary Center Analysis. Clin Genitourin Cancer 14: 89-95. https://doi.org/ 10.1016 / j.clgc.2015.09.007.

5. Aning J, Dunn J, Daugherty M, et al. Towards bloodless cystectomy: a 10-year experience of intra-operative cell salvage during radical cystectomy. BJU Int. 2012;110:E608-13. https://doi.org/10.1111/j.1464-410X.2012.11338.x.

6. Pinto MA, Chedid MF, Sekine L, et al (2019) Intraoperative cell salvage with autologous transfusion in liver transplantation. World J Gastrointest Surg 11: 11-8. https://doi.org/ 10.4240 / wj gs.v11.i1.11

7. Soubra A, Zabell JR, Adejoro O, et al (2015) Effect of perioperative blood transfusion on mortality for major urologic malignancies. Clin Genitourin Cancer 13: e173-81. https://doi.org/ 10.1016 / j.clgc.2014.12.006.

8. Linder BJ, Frank I, Cheville JC, et al (2013) The impact of perioperative blood transfusion on cancer recurrence and survival following radical cystectomy. Eur Urol 63: 839-45. https://doi.org/ 10.1016 / j.eururo.2013.01.004.

9. 10.1002

Carless PA, Henry DA, Moxey AJ, et al (2010) Cell salvage for minimising perioperative allogeneic blood transfusion. Cochrane Database Syst Rev 4: CD001888. Published 2010 Apr 14. https://doi.org/ 10.1002 / 14651858.CD001888.pub4.

10. NICE guidance: intraoperative red blood cell salvage during radical prostatectomy or radical cystectomy. (2008). IPG258. Guidance issued 23 rd April. Available at: http://www.nice.org.uk/guidance/IPG258. Accessed 1 May 2011.

11. Klein AA, Bailey CR, Charlton AJ, et al (2018) Association of Anaesthetists guidelines: cell salvage for peri-operative blood conservation 73:1141-1150. https://doi.org/10.1111/anae.14331.

12. Neves RJ, Zincke H. Surgical treatment of renal cancer with vena cava extension. Br J Urol. 1987;59:390-5. https://doi.org/10.1111/j.1464410x.1987.tb04832.x.

13. Berczi A, Flasko T, Szerafin T, et al. Surgical Management and Outcome of Renal Cell Carcinoma with Inferior Vena Cava Tumor Thrombus. Urol Int. 2017;99:267-71. https://doi.org/10.1159/000464108.

14. Chen YY, Xu GB. Effect of circulating tumor cells combined with negative enrichment and CD45-FISH identification in diagnosis, therapy monitoring and prognosis of primary lung cancer. Med Oncol. 2014;31:240. https://doi.org/10.1007/s12032-014-0240-0.

15. Delahunt B, Cheville JC, Martignoni G, et al. The International Society of Urological Pathology (ISUP) grading system for renal cell carcinoma and other prognostic parameters. Am J Surg Pathol. 2013;37:1490-504. https://doi.org/10.1097/PAS.0b013e318299f0fb.

16. Chaffer CL, Weinberg RA. A perspective on cancer cell metastasis. Science. 2011;331:1559-64. https://doi.org/10.1126/science.1203543.

17. Gwak MS, Lee KW, Kim SY, et al. Can a leukocyte depletion filter (LDF) reduce the risk of reintroduction of hepatocellular carcinoma cells? Liver Transpl. $2005 ; 11: 331-5$.

18. Li J, Shi SB, Shi WL, et al. LUNX mRNA-positive cells at different time points predict prognosis in patients with surgically resected nonsmall cell lung cancer. Transl Res. 2014;163:27-35. https://doi.org/10.1016/j.trsl.2013.09.010.

19. Kumar N, Lam R, Zaw AS, et al (2014) Flow cytometric evaluation of the safety of intraoperative salvaged blood filtered with leucocyte depletion filter in spine tumour surgery. Ann Surg Oncol 21:4330-5. https://doi.org/ 10.1245/s10434-014-3950-9.

20. Kumar N, Ahmed Q, Lee VK, et al. Are we ready for the use of intraoperative salvaged blood in metastatic spine tumour surgery? Eur Spine J. 2016;25:3997-4007.

21. Lin PP. Aneuploid CTC and CEC. Diagnostics (Basel). 2018;8:26. https://doi.org/10.3390/diagnostics8020026.

22. Wang $\mathrm{H}$, Stoecklein NH, Lin PP, Gires O. Circulating and disseminated tumor cells: diagnostic tools and therapeutic targets in motion. Oncotarget. 2017;8:1884-912. https://doi.org/10.18632/oncotarget.12242.

23. Tanaka F, Yoneda $\mathrm{K}$, Kondo N, et al. Circulating tumor cell as a diagnostic marker in primary lung cancer. Clin Cancer Res. 2009;5:6980-6. https://doi.org/10.1158/1078-0432.CCR-09-1095.

24. Spizzo G, Fong D, Wurm M, et al (2011) EpCAM expression in primary tumour tissues and metastases: an immunohistochemical analysis. J Clin Pathol 64: 415-20. https://doi.org/ 10.1136 / jcp.2011.090274.

25. Baeuerle PA, Gires O. EpCAM (CD326) finding its role in cancer. Br J Cancer. 2007;96:417-23. https://doi.org/10.1038/sj.bjc.6603494.

26. Ning $\mathrm{N}$, Zhan T, Zhang $\mathrm{Y}$, et al. Improvement of specific detection of circulating tumor cells using combined CD 45 staining and fluorescence in situ hybridization. Clin Chim Acta. 2014;433:69-75. https://doi.org/10.1016/j.cca.2014.02.019.

27. Ge F, Zhang H, Wang DD, et al. Enhanced detection and comprehensive in situ phenotypic characterization of circulating and disseminated heteroploid epithelial and glioma tumor cells. Oncotarget. 2015;6:27049-64. https://doi.org/10.18632/oncotarget.4819.

28. Kuroda N, Shiotsu T, Kawada C, et al. Clear cell papillary renal cell carcinoma and clear cell renal cell carcinoma arising in acquired cystic disease of the kidney: an immunohistochemical and genetic study. Ann Diagn Pathol. 2011;15:282-5. https://doi.org/10.1016/j.anndiagpath.2010.03.007.

29. Lan TT, Keller-Ramey J, Fitzpatrick C, et al. Unclassified renal cell carcinoma with tubulopapillary architecture, clear cell phenotype, and chromosome 8 monosomy: a new kid on the block. Virchows Arch. 2016;469:81-91. https://doi.org/10.1007/s00428-016-1952-7.

30. Dorđević G, Matušan Ilijaš K, Hadžisejdić l, et al. EGFR protein overexpression correlates with chromosome 7 polysomy and poor prognostic parameters in clear cell renal cell carcinoma. J Biomed Sci. 2012;19:40. https://doi.org/10.1186/1423-0127-19-40.

Page $7 / 12$ 
31. Pailoor J, Rajandram R, Yap NY, et al (2013) Chromosome 7 aneuploidy in clear cell and papillary renal cell carcinoma: detection using silver in situ hybridization technique. Indian J Pathol Microbiol 56:98-102. https://doi.org/ 10.4103/0377-4929.118688.

32. Shao P, Li J, Qin C, et al (2015) Laparoscopic Radical Nephrectomy and Inferior Vena Cava Thrombectomy in the Treatment of Renal Cell Carcinoma.Eur Urol 68:115-22. https://doi.org/ 10.1016/j.eururo.2014.12.011.

33. Wang YL, Jiang B, Yn FF, et al (2015) Perioperative Blood Transfusion Promotes Worse Outcomes of Bladder Cancer after Radical Cystectomy: A Systematic Review and Meta-Analysis. PLoS One 10: e0130122. Published 2015 Jun 16. https://doi.org/ 10.1371 / journal.pone.0130122.

34. Li SL, Ye Y, Yuan XH. (2017) Association between Allogeneic or Autologous Blood Transfusion and Survival in Patients after Radical Prostatectomy: A Systematic Review and Meta-Analysis. PLoS One 12: e0171081. https://doi.org/ 10.1371 / journal.pone.0171081.

35. Akchurin RS, Davidov MI, Partigulov SA, et al (1997) Cardiopulmonary bypass and cell-saver technique in combined oncologic and cardiovascular surgery. Artif Organs 21: 763-5. https://doi.org/ 10.1111/ j.1525-1594.1997.tb03738.x.

36. Moskowitz DM, Perelman SI, Cousineau KM, et al. Multidisciplinary management of a Jehovah's Witness patient for the removal of a renal cell carcinoma extending into the right atrium. Can J Anaesth. 2002;49:402-8. https://doi.org/10.1007/BF03017330.

37. Casey RG, Raheem OA, Elmusharaf E, et al (2013) Renal cell carcinoma with IVC and atrial thrombus: a single centre's 10 year surgical experience. Surgeon 11:295-9. https://doi.org/ 10.1016/j.surge.2013.02.007.

38. Lyon TD, Ferroni MC, Turner RM 2nd, Jones C, Jacobs BL, Davies BJ. (2015)Short-term Outcomes of Intraoperative Cell Saver Transfusion During Open Partial Nephrectomy. Urology 86: 1153-8. https://doi.org/ 10.1016/ j.urology. 2015.09.008.

39. Kinnear N, Hua L, Heijkoop B, et al (2019) The impact of intra-operative cell salvage during open nephrectomy. Asian J Urol 6:346-52. https://doi.org/ 10.1016/j.ajur.2018.06.008.

40. Kinnear N, O'Callaghan M, Hennessey D, et al (2019) Intra-operative cell salvage in urological surgery: a systematic review and meta-analysis of comparative studies. BJU Int 123: 210-9. https://doi.org/ 10.1111 / bju.14373.

41. Hansen E, Bechmann V, Altmeppen J. (2002) Intraoperative blood salvage in cancer surgery: safe and effective Transfus Apher Sci 27: $153-157$. https://doi.org/ 10.1016 / s1473-0502 (02) 00037-x.

42. Hansen E, Wolff N, Knuechel R, et al (1995) Tumor cells in blood shed from the surgical field. Arch Surg 130: 387-93. https://doi.org/ 10.1001 / archsurg.1995.01430040049007.

43. Mei K, Du L, Yan M, et al (2015) Modified Leukocyte Filter Removes Tumor Cells from the Salvaged Blood. PLoS One 10: e0130864. Published 2015 Jun 22. https://doi.org/ 10.1371 / journal.pone.0130864.

\section{Tables}

Table 1

Patients' demographic information, follow-up and tumor pathological classification.

\begin{tabular}{|c|c|c|c|c|c|c|c|c|c|}
\hline Case & Age (y) & Gender & $\begin{array}{l}\text { Mayo-level } \\
\text { grading }\end{array}$ & $\begin{array}{l}\text { Surgical } \\
\text { duration (min) }\end{array}$ & $\begin{array}{l}\text { Tumor size } \\
\text { (cm) }\end{array}$ & $\begin{array}{l}\text { WHO/ISUP } \\
\text { grading }\end{array}$ & $\begin{array}{l}\text { Pathological } \\
\text { diagnosis }\end{array}$ & $\begin{array}{l}\text { 20-mon } \\
\text { follow-up }\end{array}$ & $\begin{array}{l}\text { Tumor recurrence } \\
\text { or metastasis }\end{array}$ \\
\hline 1 & 63 & $M$ & प & 553 & $7.1 * 5.2 * 4.6$ & $\mathrm{G} 2$ & $\operatorname{ccRCC}$ & alive & none \\
\hline $2^{*}$ & 49 & $M$ & प & 350 & - & - & ccRCC & dead & $\begin{array}{l}\text { Preoperative } \\
\text { lung metastasis }\end{array}$ \\
\hline 3 & 48 & $M$ & 口 & 161 & $12 * 10 * 6$ & G3 & ccRCC & alive & none \\
\hline 4 & 75 & $M$ & प & 320 & $5 * 3 * 2.5$ & $\mathrm{G} 2$ & ccRCC & alive & none \\
\hline 5 & 60 & $\mathrm{~F}$ & प & 540 & $9 * 5 * 4$ & G3 & $\operatorname{ccRCC}$ & alive & none \\
\hline
\end{tabular}

*, The patient underwent radical right nephrectomy for renal cancer 3 years ago. Now he was diagnosed as inferior vena cava thrombus with lung metastasis. The patient died of emphysema 16 months after surgery.

ISUP, International Society of Urological Pathology. G2, Tumour cell nucleoli conspicuous and eosinophilic at $400 \times$ magnification and visible but not prominent at $100 \times$ magnification; G3, Tumor cell nucleoli conspicuous and eosinophilic at $100 \times$ magnification.

ccRCC, clear cell Renal Cell Carcinoma. 
Table 2

Intraoperative blood loss and the transfusion.

\begin{tabular}{|lllll|}
\hline Case & Total blood loss $(\mathrm{ml})$ & Infused RBC $(\mathrm{ml})$ & Infused plasma (ml) & Recovered blood (ml) \\
\hline 1 & 2700 & 2000 & 0 & 1300 \\
\hline 2 & 1500 & 1200 & 400 & 750 \\
\hline 3 & 200 & 0 & 0 & 100 \\
\hline 4 & 2100 & 2000 & 800 & 1000 \\
\hline 5 & 4000 & 3600 & 1600 & 2000 \\
\hline Median & 2100 & 2000 & 400 & 1000 \\
\hline QR (ml) & $1500-2700$ & $1200-2000$ & $0-800$ & $750-1300$ \\
\hline IQR, inter quartile range. & & & \\
\hline
\end{tabular}


Table 3

CTC counts of aneuploidy of chromosome 8 and/or 7 from blood samples.

\begin{tabular}{|c|c|c|c|c|c|c|c|c|c|c|c|}
\hline \multirow[t]{2}{*}{ Case } & \multirow[t]{2}{*}{ Sample } & \multicolumn{10}{|l|}{ CTC counts } \\
\hline & & $\begin{array}{l}\text { Triploid of } \\
\text { chromosome } \\
8\end{array}$ & $\begin{array}{l}\text { Tetraploid of } \\
\text { chromosome } \\
8\end{array}$ & $\begin{array}{l}\text { Polydiploid } \\
\text { ( } ₫ 4) \text { of } \\
\text { chromosome } \\
8\end{array}$ & $\begin{array}{l}\text { Triploid of } \\
\text { chromosome } \\
7\end{array}$ & $\begin{array}{l}\text { Tetraploid of } \\
\text { chromosome } \\
7\end{array}$ & $\begin{array}{l}\text { Polydiploid } \\
\text { ( } \varangle 4 \text { ) of } \\
\text { chromosome } \\
7\end{array}$ & $\begin{array}{l}\text { Polydiploidy } \\
\text { chromosome } \\
\text { of both } 7 \\
\text { and } 8\end{array}$ & CTM & Sum & $\begin{array}{l}\text { Tot } \\
\text { nun }\end{array}$ \\
\hline \multirow[t]{5}{*}{1} & S1 & 3 & & & & & & & & 3 & \\
\hline & S2 & & & & & & & & & & \\
\hline & S3 & 1 & & & & & & & & 1 & \\
\hline & S4 & & & & & & & & & & \\
\hline & & & & & & & & & & & 4 \\
\hline \multirow[t]{5}{*}{2} & $\mathrm{~S} 1$ & 1 & & & 2 & & & $1 *$ & & 4 & \\
\hline & $\mathrm{S} 2$ & & & & & & & & & & \\
\hline & S3 & & & & 1 & & & & & 1 & \\
\hline & S4 & & & & & & & & & & \\
\hline & & & & & & & & & & & 5 \\
\hline \multirow[t]{5}{*}{3} & $\mathrm{~S} 1$ & 6 & 1 & & 3 & & & & & 10 & \\
\hline & $\mathrm{S} 2$ & 1 & & & 1 & & & & 1 & 3 & \\
\hline & S3 & & & & & & & & & & \\
\hline & S4 & & & & & & & & & & \\
\hline & & & & & & & & & & & 13 \\
\hline \multirow[t]{5}{*}{4} & S1 & 4 & & & 3 & & & & & 7 & \\
\hline & $\mathrm{S} 2$ & 3 & & & 1 & & & $1 *$ & & 5 & \\
\hline & S3 & & & & & & & & & & \\
\hline & S4 & & & & & & & & & & \\
\hline & & & & & & & & & & & 12 \\
\hline \multirow[t]{5}{*}{5} & $\mathrm{~S} 1$ & 1 & & & 1 & & & $1^{*}$ & & 3 & \\
\hline & $\mathrm{S} 2$ & & & & 1 & & & & & 1 & \\
\hline & S3 & & & & & & & & & & \\
\hline & S4 & & & & & & & & & & \\
\hline & & & & & & & & & & & 5 \\
\hline \multicolumn{12}{|c|}{$\begin{array}{l}\text { Tumor cells were recognized and counted using immunostaining and fluorescence in situ hybridization technology. Only cells with CD45-/DAPI+/CEP8+( } ₫ 2) \text {, } \\
\text { CD45-/DAPI+/CEP8+ ( } ₫ 2) \text {, and CD45-/DAPI+/CEP8 + and CEP7+ (hyperdiploidy) were identified as CTCs. }\end{array}$} \\
\hline \multicolumn{12}{|c|}{ Number 0 were not shown in the table. } \\
\hline \multicolumn{12}{|c|}{ *, triploid of both chromosome 8 and 7} \\
\hline \multicolumn{12}{|c|}{ CTM, Circulating Tumor Microemboli. } \\
\hline \multicolumn{12}{|c|}{ S1, peripheral venous blood sample from internal jugular vein before skin incision, indicative of the circulating tumor cells; } \\
\hline \multicolumn{12}{|c|}{ S2, blood sampled in he vena cava around thrombus during surgery, indicating direct cells shedding in surgical manipulation; } \\
\hline s3, blc & od after 10 & S washing and & pefore LDF filter & g, which repres & nts the tumor $\mathrm{ce}$ & I cleaning effica & $y$ with only IOC & & & & \\
\hline
\end{tabular}


Case number of aneuploidy of chromosome 7 and/or 8 .

\begin{tabular}{|c|c|c|c|c|}
\hline \multirow[t]{3}{*}{ sample } & \multicolumn{4}{|c|}{ Case numbers } \\
\hline & \multirow[t]{2}{*}{ chromosome 8 triploidy } & \multirow[t]{2}{*}{ chromosome 8 tetraploidy } & \multirow[t]{2}{*}{ chromosome 7 triploidy } & \multirow{2}{*}{$\begin{array}{l}\text { Chromosome } \\
7 \text { and } 8 \text { hyperdiploidy }\end{array}$} \\
\hline & & & & \\
\hline S1 & 5 & 1 & 4 & 2 \\
\hline S2 & 2 & & 3 & 1 \\
\hline S3 & 1 & & 1 & \\
\hline \multicolumn{5}{|l|}{ S4 } \\
\hline Total & 8 & 1 & 8 & 3 \\
\hline \multicolumn{5}{|c|}{ Triploidy of chromosome 8 were detected in 8 cases: $5 / 5$ cases in S1, 2/5 cases in S2 and 1/5 cases in S3; } \\
\hline \multicolumn{5}{|c|}{ Triploidy of chromosome 7 were detected in 8 cases: $4 / 5$ cases in $S 1,3 / 5$ cases in $S 2$, and 1/5cases in S3; } \\
\hline \multicolumn{5}{|c|}{ The hyperdiploidy of both chormosome 7 and 8 were detected in 3 cases: 2 cases of S1 and 1 case of S2; } \\
\hline \multicolumn{5}{|c|}{ Only 1 case with tetraploidy of chromosome 8 ; } \\
\hline \multicolumn{5}{|c|}{ No tetraploidy of chromosome 7 , or other aberrant chromosome number $\geq 4$ were detected. } \\
\hline
\end{tabular}

\section{Figures}

\section{Peripheral venous blood before skin incision}

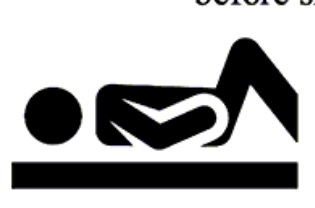

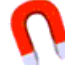

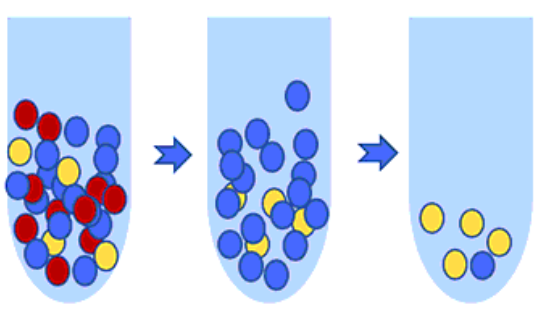

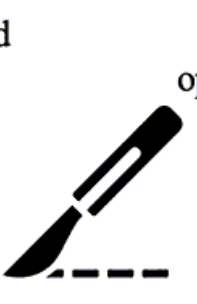

S1

Blood from operative field
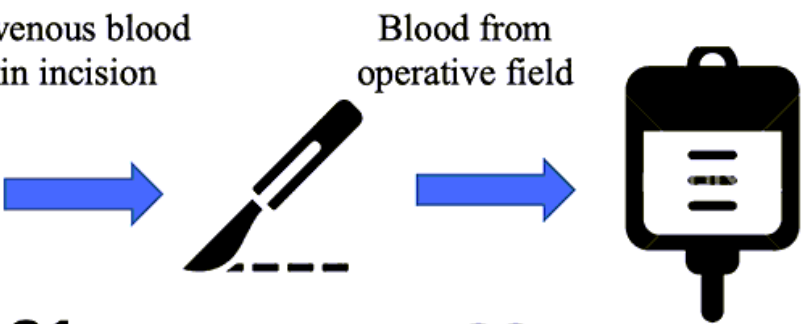

S2

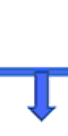

Blood sampled after IOCS
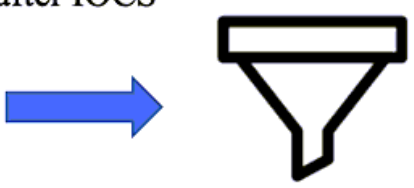

S3
Blood sampled after IOCS-LDF

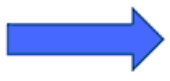

S4

Negative enrichment and iFISH
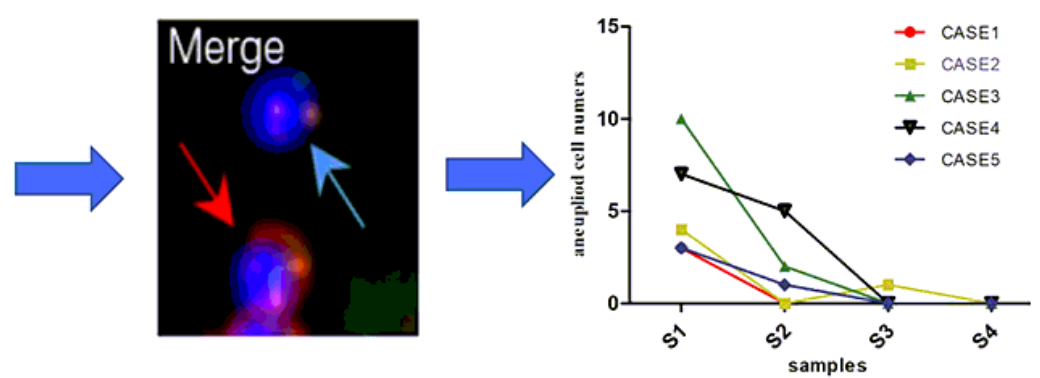

Figure 1

Schematic plot of sample collection and processing. 

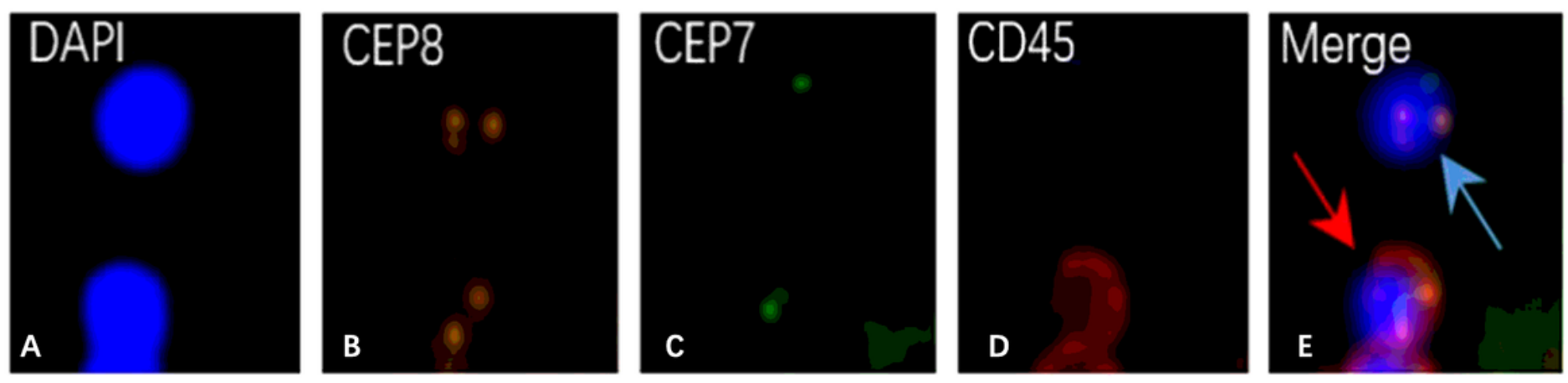

\section{Figure 2}

Pathological examination of the dissected renal tumor and thrombus. All five patients were diagnosed as ccRCC. A and B, histological examination showing the ccRCC as WHO/ISUP grade 2 (hematoxylin and eosin, original magnification: $A, \times 100 ; B, \times 200$ ). C and D, histological examination showing the ccRCC as WHO/ISUP grade 3 (hematoxylin and eosin, original magnification: $C, \times 100 ; D \times 200$ ).


Figure 3

Detection and identification of tumor cells of renal cancer by immunostaining and fluorescence in situ hybridization technique (FISH). CTCs (blue arrow) were examined and identified as hyperdiploid CEP8+/DAPI+/CD45-, hyperdiploid CEP7+/DAPI+/CD45- and hyperdiploid CEP7+, CEP8+/DAPI+/CD45- by two independent pathologists, while cells with CD45+ were differentiated as WBC (red arrow). CEP, centromere polyploidy. 